\title{
PSIQUIATRIA E NATURALIZAÇÃO DO CRIME PASSIONAL NO RIO DE JANEIRO DA DÉCADA DE 1930
}

Psychiatry and naturalization of passional crime in Rio de Janeiro in the $1930 \mathrm{~s}$

Psiquiatría y naturalización del delito pasivo en Río de Janeiro desde los años 30

\author{
ELIZA TEIXEIRA DE TOLEDO ${ }^{\text {* }}$ \\ ALLISTER ANDREW TEIXEIRA DIAS ${ }^{\mathrm{II}^{* *}}$
}

DOl: http://dx.doi.org/10.1590/S2178-149420200002000010

'Casa de Oswaldo Cruz, Fundação Oswaldo Cruz (COC-Fiocruz) - Rio de Janeiro (RJ), Brasil.

*Pós-doutoranda em História das Ciências e da Saúde pela COC-Fiocruz (elizattoledo@gmail.com).

(D) https://orcid.org/0000-0002-6687-1787

"Instituto de Estudos de Saúde Coletiva, Universidade Federal do Rio de Janeiro (IESC/UFRJ) - Rio de Janeiro (RJ), Brasil.

**Professor Substituto do IESC/UFRJ (allisterdias@hotmail.com).

(D) https://orcid.org/0000-0003-1882-4211

Artigo recebido em 01 de janeiro de 2020 e aprovado para publicação em 20 de março de 2020. 


\title{
RESUMO
}

Este artigo visou contribuir para a historicização da violência de gênero no Brasil por meio da análise de casos de crimes passionais presentes nas páginas do periódico Arquivos do Manicômio Judiciário do Rio de Janeiro na década de 1930, momento em que tais crimes ganharam contornos de problema social com a efervescência do debate público a seu respeito. Assim, por meio de laudos psiquiátricos, jurisprudência e pareceres do Conselho Penitenciário do Distrito Federal publicados no periódico, o texto analisa a reificação e a naturalização da violência contra as mulheres no âmbito da psiquiatria forense do Rio de Janeiro (RJ) e 0 embate desta com outros posicionamentos.

PALAVRAS-CHAVE: Violência de gênero; Crime passional; Psiquiatria; Justiça penal; Heitor Carrilho.

\begin{abstract}
This article aims to contribute to the historicization of gender violence in Brazil based on the analysis of cases of "crimes of passion" present in the periodical Archives of the Judicial Asylum in Rio de Janeiro in the 1930s, when such crimes acquired the status of a social problem with the effervescence of public debates about it. Thus, through psychiatric reports, jurisprudence and opinions from the Penitentiary Council of the Federal District published in this periodical, the text analyzes the reification and naturalization of violence against women within the scope of forensic psychiatry in Rio de Janeiro and its confrontation with other positions.
\end{abstract}

KEYWORDS: Gender violence; Crime of passion; Psychiatry; Criminal justice; Heitor Carrilho.

\section{RESUMEN}

Este artículo tiene como objetivo contribuir a la historización de la violencia de género en Brasil a partir del análisis de casos de "crímenes pasionales" presentes en las páginas de los Archivos periódicos del Asilo Judicial en Río de Janeiro en la década de 1930, época en que tales crímenes adquirieron contornos de problema social con la efervescencia del debate público al respecto. Así, mediante informes psiquiátricos, jurisprudencia y opiniones del Consejo Penitenciario del Distrito Federal de la publicación, el texto analiza la reificación y naturalización de la violencia contra las mujeres en el ámbito de la psiquiatría forense en Río de Janeiro y su confrontación con otros cargos.

PALABRAS CLAVE: Violencia de género; Crimen pasional; Psiquiatría; Justicia penal; Heitor Carrilho. 


\section{INTRODUÇÃO}

E ste artigo teve por pressuposto historiográfico e ético-político primacial a noção de que historicizar e, portanto, desnaturalizar a violência de gênero constitui ferramenta fundamental na luta contra ela. Não é demais lembrar, já nesta introdução, que a própria Lei Maria da Penha esbarra, por vezes, no mau acolhimento às denúncias em função da aceitação cultural da violência contra a mulher. Isso contribui para a diminuição da responsabilidade do agressor, naturalizando a experiência da violência como parte do devir feminino (Corrêa, 1983). Nesse sentido, entendemos que a abordagem histórica arqueogenealógica capacita a compreensão dos estratos de continuidade de ideias e representações atuais sobre violência de gênero, especialmente na sua dimensão dita doméstica, como: a ideia de que tal tipo de violência é mais recorrente em certos segmentos sociais; a distinção entre violência física e simbólica, ou violência real e potencial; ou, ainda, a representação desse tipo de violência como ato privado, de não intervenção, entre outras (Foyster, 2005).

Aqui, debruçamo-nos sobre a documentação histórica de natureza médico-jurídica, toda publicada nos Arquivos do Manicômio Judiciário do Rio de Janeiro. Levantamos um total de 23 casos de crime passional nos quais, de alguma maneira, ocorreu intervenção sistemática do saber psiquiátrico, fosse em laudos periciais de homens tidos por passionais que passaram por exame no Manicômio Judiciário do Rio de Janeiro (MJRJ); fosse em jurisprudência relativa a casos que passaram pelo Tribunal do Júri ou pela segunda instância da justiça criminal do Distrito Federal, a Corte de Apelação do Distrito Federal; fosse em caso sob apreciação do Conselho Penitenciário do Distrito Federal (CPDF). Em virtude do espaço, não abordamos todos os casos, somente os que apresentavam elementos analíticos mais substanciosos. Todos os casos dizem respeito a acusados ou condenados que acionaram em sua defesa o parágrafo $4^{\circ}$ do artigo 27 do Código Penal vigente pela maior parte do período, o Código Penal de 1890 (BRASIL, 1890). Tal dispositivo dava por irresponsável o indivíduo que cometesse o crime em estado de completa perturbação dos sentidos e da inteligência.

Não é possível, na maioria dos casos analisados, saber a totalidade do processo penal (condenação ou absolvição etc.), mas, como já apontado, isso tem pouco impacto no nosso objetivo primacial, que é destacar a injunção do discurso psiquiátrico e suas assunções de gênero em casos de violência como os que serão abordados. A opção metodológica pelo estudo de casos não afasta a perspectiva que compreende a violência de gênero como sistêmica e estruturante das relações sociais do contexto sob foco. Assim, perseguem-se, aqui, os modos de reprodução e reificação da violência contra a mulher segundo o universo discursivo específico da psiquiatria forense do Rio de Janeiro (RJ). 
A literatura nas ciências humanas e sociais que se debruçou sobre a história dos crimes passionais ${ }^{1}$ vem mostrando o quanto influxos de classe, raça e gênero emergem na documentação periodística, policial, médica e jurídica que enredam discursivamente esses $\operatorname{casos}^{2}$. São histórias de vidas somente passíveis de conhecimento e reconstrução histórica pela violência que experimentaram. Nisso despontam o estudo aprofundado das práticas discursivas relativas à honra, o estudo das sensibilidades e atitudes populares, especialmente das percepções dos papéis de homens e mulheres, família e casamento, e o quanto revelam de transformações nos ideais de masculinidade e feminilidade, das práticas sexuais e amorosas etc. (Caulfield, 2000; Esteves, 1989).

A questão da honra e dos valores sexuais estava em plena discussão no Rio de Janeiro das décadas de 1910, 1920 e 1930, sendo muito forte, para muitos membros das elites letradas, a noção de que a honestidade sexual das mulheres configurava alicerce da família, que, por sua vez, constituía base da nação (Caulfield, 2000). Nesse sentido, vem sendo investigada a forma como o imperativo do cumprimento de valores de masculinidade e de virilidade hegemônicos e a desqualificação da vítima mulher pelo viés da sua presumida imoralidade operaram no interior dos discursos médicos e jurídicos (Strange et al., 2014). Tais valores, expressos em boa parte do discurso psiquiátrico do período, participaram, ainda, do enraizamento da significação comumente aceita de que o desvio feminino seria razão de ser, parcial ou total, do desequilíbrio psicológico masculino. Historiografia importante segue nesse sentido, mostrando o quanto expectativas de papéis de gênero, posição social de agressor e vítima influenciavam, dessa maneira, a percepção que se tinha da presumida doença e/ou anormalidade do perpetrador do crime (Rinaldi, 2015; Harris, 1993; Strange et al., 2014).

Ademais, tensões em torno de relações de gênero nas mais diversas esferas sociais tornaram-se latentes nesse contexto. No Brasil, entre as décadas de 1920 e 1940, houve crescimento do trabalho fabril feminino em alguns centros urbanos, como no Rio de Janeiro e em São Paulo (SP). Aumentavam também as possiblidades de emprego em estabelecimentos bancários e comerciais. 0 magistério mantinha-se uma opção de maior status social para algumas mulheres, sobretudo em função do acesso a ambientes intelectualizados e funções públicas. A enfermagem, profissão historicamente feminina, estruturava-se profissionalmente no país, com escolas sendo fundadas em vários pontos do país entre as décadas de 1930 e 1940, como no Rio de Janeiro, em São Paulo, em Belo Horizonte (MG) e em Salvador (BA). Mesmo ocupando novas esferas do mercado produtivo, apenas em 1943 as mulheres adquiriram o direito de trabalhar sem a autorização do marido. Também naquele ano, no item "Da proteção ao trabalho da mulher" da Consolidação das Leis do Trabalho, estabelecia-se sua equiparação salarial com os homens, ainda que ilegalidades e discriminações na esfera 
do trabalho não tenham sido suplantadas com essas medidas (Matos e Borelli, 2013: 141). Além disso, foi apenas com o Estatuto da Mulher Casada, em 1962, que o direito do marido de impedir que a esposa trabalhasse fora de casa foi retirado do Código Civil (Matos e Borelli, 2013). Nessa configuração, o avanço feminino na esfera do trabalho público chocava com algumas limitações de ordem social e cultural que permaneciam regidas pelas leis.

Do ponto de vista penal, a codificação de 1890 negou ao homem o "direito tradicional de defender a honra da família (e pessoal) por meio do assassinato da mulher adúltera" (Caulfield, 2000: 84), mesmo assim, negociou-se o espaço para a absolvição de uxoricidas por meio da dirimente da completa perturbação dos sentidos e da inteligência, dando espaço para a efervescência de campanhas contra os uxoricidas na Primeira República.

Nesse contexto, os discursos psiquiátricos, veiculados por artefatos como laudos, textos e publicações variadas, influenciaram sobremaneira na naturalização da violência contra a mulher ao patologizar seu perpetrador e ao dissociar motivação de tais violências das raízes socio-históricas que as amparavam e amparam. Cabe esclarecer neste ponto que por naturalização compreendemos a atribuição de "qualidades essenciais ao que na verdade é fruto de atividades humanas" (Jesús, 2011). O processo de naturalização em nossa análise se daria como o efeito de teorias biológicas de diferenciação sexual produzidas/reproduzidas dentro das teorias psiquiátricas. Tal processo, amparado por noções organicistas/biologizantes como a noção de temperamento que será abordada mais adiante — , participa da dissimulação e da reprodução de fatores sociais da violência, contribuindo para sua aceitação como não problemática.

Nos discursos médicos do século XIX surgiu a argumentação de que tais crimes eram cometidos por estados patológicos, gerados pelo excesso de amor masculino (Secreto, 2005: 212). Isso, no período em tela, ganhara caráter específico pelo influxo das teorias psicopatológicas do constitucionalismo kretschmeriano, cujo conteúdo será exposto na parte seguinte deste artigo. 0 que nos cabe buscar compreender aqui é de que forma argumentos como a hiperemotividade e a exaltação emotiva de acusados de crimes passionais tornaram-nos pacientes, doentes irresponsabilizados por seus crimes.

Aqui reside um ponto importante na documentação analisada: muitos dos acusados de crimes passionais não tinham, previamente ao assassinato ou à sua tentativa, comportamento considerado socialmente desviante ou fora da norma a ponto de terem sido tachados de loucos, seja no mundo leigo, seja no mundo médico, jurídico ou policial. Muitos eram considerados sujeitos de bem. Este artigo propôs, então, a investigação histórica de como um campo específico do saber médico, o saber psiquiátrico, envolveu-se com o fenômeno histórico dos crimes passionais e respondeu a ele, dimensão e expressão histórica da violência 
contra a mulher no Brasil. Priorizamos neste recorte os crimes de homens contra mulheres ao longo dos anos 1930, maioria na documentação analisada.

Esse recorte e esse foco nos anos 1930 justificam-se em várias dimensões, as quais, embora arroladas aqui em certa ordem narrativa, não apresentam relação de hierarquia em termos de importância. Primeiramente, a historiografia consolidada (e já citada) bate na tecla de que 0 assassinato de mulheres e de outros homens por motivos reconhecidamente passionais ganharam no debate público, na jurisprudência e na prática psiquiátrica maior atenção, de maneira especial nos anos 1920 e mais intensamente nos anos 1930. Era momento de combate intelectual e formação de constructos teóricos fornecedores de inteligibilidade para 0 amplo espectro de quadros enquadrados sob a rubrica de crimes passionais. Não à toa, houve tradução para português, no mesmo ano, 1934, das duas principais reflexões internacionais sobre o assunto: 0 Crime Passional, de L. Rabnowicz, e Delito Passional na Civilização Contemporânea, de Enrico Ferri.

Em segundo lugar, era momento no qual, uma década depois do início de funcionamento do MJRJ, a função psiquiátrico-forense pericial estava consolidada e aceita no mundo jurídico (Carrilho, 1932); relacionado a isso, observava-se maior respaldo dos discursos de cunho médico e psicológico entre os magistrados, sobretudo aqueles do Tribunal do Júri, que julgam tais crimes ${ }^{3}$. Terceiro, era momento, mais especificamente em 1933, de convergência na fundação da Sociedade Brasileira de Criminologia de movimento intelectual masculino do mundo médico e jurídico, que tinha por bandeira a luta contra os crimes passionais (Dias, 2015). Por fim, esse período é significativo por ser o de maior efervescência nas primeiras 40 décadas da República em termos de debates e propostas de reformulação das leis penais, mas sobretudo de questionamento da dirimente da completa perturbação dos sentidos e da inteligência (último decênio de sua vigência). Em suma, uma plêiade de elementos que fazem convergir o olhar investigativo acerca desse objeto (discurso psiquiátrico sobre os crimes passionais) para esse momento histórico.

\section{CiÚME PATOLÓGICO, INFIDELIDADE E CONSTITUIÇÕES PSICOFÍSICAS}

No discurso psiquiátrico presente nos laudos, mas também em textos e documentos de natureza variada, os temas do ciúme, ou, na terminologia psicopatológica do entreguerras, ciúme patológico, e da infidelidade feminina figuraram na exculpabilização de homens que matavam mulheres e/ou outros homens por razões passionais. Os laudos do MJRJ são ricos nesse sentido. Para a psiquiatria da época, o ciúme era um afeto potencialmente gerador de forte abalo moral, terminologia muito vigente no Tribunal do Júri e na Justiça Penal de ma- 
neira geral. A isso as defesas jurídicas estavam muito atentas, quase sempre questionando 0 potencial desse afeto e da infidelidade na gestação dos crimes passionais (Dias, 2015).

Rinaldi Garzo4 ${ }^{4}$, branco, italiano de Roma, 55 anos, sapateiro, assassinou com 12 facadas o português Mario Gonçalves. No relato pericial que fizeram do italiano, com base em exame no MJRJ, os médicos Heitor Carrilho ${ }^{5}$, diretor daquela instituição médico-penal, e Morethzohn Barbosa, médico legista da polícia, destacaram sua vida honesta e trabalhadora. No Rio de Janeiro o imigrante prosperou, abrindo uma loja de sapatos, casando-se e tendo oito filhos. Porém, passou a manifestar ciúmes patológicos da mulher e, sobretudo, de suas conversas (no relato de Rinaldi) com Mario. Ademais, na avaliação dos peritos, tais ideias sobrevieram na fase involutiva da vida, marcada, no caso em apreço, por mórbida hiperestesia afetiva (Carrilho e Barbosa, 1936: 101). Nesse caso, para o médico, o italiano não poderia ser condenado pelo assassinato, já que a conjunção de ciúme patológico, sentimento de inferioridade dado pela idade avançada e sua constituição hiperemotiva fê-lo viver forte abalo moral e perder as faculdades críticas de raciocínio (Carrilho e Barbosa, 1936: 106).

Sabe-se que é do século XIX a questão de que "um indivíduo poderia parecer são na maior parte dos aspectos, mas matar como resultado direto de um defeito específico da mente" (Watson, 2011: 79). No início do século XX, o pensamento psicopatológico refinou a ideia de possíveis inconsciências ou loucuras momentâneas e, mais ainda, de estados, constituições e temperamentos não exatamente patológicos, mas na fronteira entre sanidade e doença mental. Nesse sentido, a maior parte das avaliações de criminosos passionais sob foco parte dos estudos constitucionalistas do psiquiatra alemão de Ernst Kretschmer (1888-1964), referência de inteligibilidade fundamental na psiquiatria criminológica carioca dos anos 1920, 1930 e 1940. Seu livro de 1921, Körperbau und Charakter ${ }^{6}$, teve impacto importante aqui, de forma direta e indireta.

As investigações de Kretschmer, publicadas em 1921 e continuadas e reformuladas até o pós-Segunda Guerra, tinham por interesse desvendar as relações entre o psiquismo e a forma corporal. A teoria kretschmeriana baseava-se em três conceitos centrais: constituição, caráter e temperamento. Constituição era o "conjunto de todas as qualidades individuais baseadas na herança, isto é, de enraizamento genotípico" (Kretschmer, 1947: 12-15), em relação com os estímulos externos. 0 caráter dizia respeito à dimensão psicológica, a "totalidade das possibilidades afetivo-volitivas de reação de uma pessoa" (Kretschmer, 1947: 12-15) ao longo da vida. Seria a parte psíquica da constituição, o edifício da personalidade. Por último, o temperamento era composto dos aparatos anímicos, os quais permitiam o processamento dos estímulos psíquicos, e dos humores, aparelho neuroglandular (Kretschmer, 1947). Kretschmer (1947) defendia a ideia de que a humanidade era composta de três tipos 
corporais: leptossômicos (astênicos), atléticos e pícnicos. Havia ainda o grupo heterogêneo dos displásicos, que não se encaixavam em nenhum dos anteriores ${ }^{7}$. Do ponto de vista dos temperamentos, os leptossômicos eram considerados esquizotímicos, ou seja, variantes entre dois polos (hipersensibilidade e frieza).

Na temática criminal, Kretschmer (1947) afirmava a necessidade do diagnóstico pluridimensional do delinquente, o que significava o desvelamento das várias causas para os comportamentos delinquenciais, cada qual com o seu peso: a base hereditária e constitucional da personalidade, as reações psíquicas ao ambiente e, por fim, fatores somáticos externos (alcoolismo, doenças, traumatismos etc.) (Kretschmer, 1947: 283). Para o psiquiatra alemão, a observação pluridimensional de um criminoso passional, por exemplo, seguia, necessariamente, o seguinte roteiro: na raiz uma constituição psicopática esquizoide, caracterizada por um fechamento em si; em decorrência, pouco contato social e problemas na evolução sexual, o que atravancaria a vida afetiva; a psicorreatividade passava a se caracterizar por uma neurose crônica do valor próprio. A grande tensão intrapsíquica decorrente levava ao crime (Kretschmer, 1947: 51-52).

Tais constructos kretschmerianos, principalmente o conceito de constituição, formaram muitos pensamentos e práticas médico-criminológicas, em vários contextos, sobretudo no âmbito das perícias psiquiátrico-forenses no Rio de Janeiro a partir de fins dos anos 1920. A psiquiatria forense praticada aqui nos anos 1930 buscou ser e projetou para si uma imagem de psiquiatria da totalidade, ou seja, de investigação absoluta e casada de constituição, caráter e temperamento. 0 constitucionalismo psicopatológico de Kretschmer foi aqui apropriado dando gradações à anormalidade e ao passionalismo. Apresenta-se, desse modo, um conjunto de ideias que explicam o crime por um processo psicopatológico interior, subjetivo, mas ao mesmo tempo com expressões orgânicas — quase numa dimensão biossubjetiva.

Vale uma consideração a respeito: a psiquiatria carioca dos anos 1930, longe de ser uma prática discursiva homogênea, nos seus pontos em comum com a prática pericial, estava atenta à vida e aos processos psíquicos, nos afetos, mas também nas constituições; na hereditariedade, mas também na complexidade da vida psíquica consciente e inconsciente (psicanálise); na eugenia, mas também no laboratório; na neurologia, mas também na clínica. Ou seja, a psiquiatria praticada no Rio de Janeiro não pode ser reduzida a homogênea rubrica de organicista, não obstante muitas apostas e posições mais fisicalistas, muitas das quais ancoradas nos novos aportes advindos de estudos endocrinológicos e da biotipologia.

Seguindo esse cânone, mas construindo abordagem própria e multifacetada, em várias intervenções ao longo dos anos 1930, Heitor Carrilho (1933: 49) enfatizou a necessidade de romper com a noção cultural vigente de que em certas pessoas e sob certas circunstâncias 0 
amor poderia levar a assassinatos sem culpa. 0 grande ponto de suas preocupações, no entanto, dizia respeito à distinção pericial do passionalismo verdadeiro, ou seja, dos indivíduos que poderiam ser considerados verdadeiros passionais daqueles que não poderiam ser assim adscritos cientificamente.

Se por um lado, para ele, o passional falso agia pautado em vingança, frieza, com sentimentos inferiores e anomalias éticas, o verdadeiro, com sentimento moral íntegro, agia em um estado psicoconstitucional anormal (Kretschmer, 1947) de alta impressionabilidade nervosa. Assim, e essa era a tese que Carrilho (1936: 5) defendeu ao longo dos anos 1930, os verdadeiros passionais eram esquizotímicos hipersensíveis, categoria kretschmeriana. Indivíduos de bom passado, durante o crime, agiam por paroxismo passional anulador da vontade, por isso os peritos deveriam perscrutar toda a vida social e psíquica, só assim podendo atingir a verdade de uma constituição passional afetada por um traumatismo afetivo (Carrilho, 1936: 12).

0 certo é que foi forjado relativo consenso na comunidade criminológica carioca do período que passava pela condenação do romantismo — seja literário, seja em outros suportes, a ficcionalização e a romantização desse tipo de criminalidade que emerge na literatura oitocentista - e a necessidade de construção de constructos validados como científicos que dessem conta de definir sujeitos (no geral homens) verdadeiramente, ou, patologicamente, passionais. Não sendo a psiquiatria um bloco discursivo uníssono e homogêneo a esse respeito, Afrânio Peixoto (1933), intelectual e psiquiatra polígrafo, personagem central não só da comunidade psiquiátrica e criminológica, mas também do campo intelectual e político da cidade, mantinha leitura crítica e mais alargada do problema, criticando o capitalismo e os hábitos das classes abastadas, trazendo dimensões socioculturais do problema que não passavam por definição científica da verdadeira criminalidade passional.

No mundo jurídico, o promotor Roberto Lyra (1932: 134), opositor importante das intervenções de Carrilho e um dos protagonistas homens do combate da criminalidade passional, aceitava, contudo, o conceito de verdadeiros passionais, ou passionalidade verdadeira. Seguindo Carrilho (1936, p.33-59), os verdadeiros passionais eram sujeitos jovens e introspectivos, com bons antecedentes sociais, sensibilidade exagerada, quase patológica, os quais não ocultavam nem premeditavam seus crimes. Para o promotor, assim como para Carrilho, as constituições hiperemotivas desses indivíduos manifestavam-se em sintomas físicos: reflexos exagerados, sentidos, sensações e reações vasomotoras desequilibradas, problema no aparelho digestivo, irregularidades no ritmo da respiração e do coração, tremores etc. Assim, o crime verdadeiramente passional relacionava personalidade, fisiologia e paixão (Lyra, 1932: 137). 0 ciúme, nesse quadro, era um afeto desencadeador, porém a definição e o desvela- 
mento dessa condição anormal/patológica de uma verdadeira passionalidade era objeto de disputa em cada caso.

Mas não apenas os ciúmes motivados por desconfianças agiram na percepção dos atos de violência desses homens segundo rompantes hiperemotivos. Em um caso emblemático de violência contra a parceira que repercutiu nos jornais cariocas, podemos ver também os ciúmes com relação à integralidade da vida da mulher, da sua história, emergindo no discurso pericial e mesmo no dos próprios criminosos homens. Fernando Vasconcelos, branco, professor de humanidades, casou-se com Elaine Carvalho (mulher cuja biografia não deixou rastro na documentação, algo comum nesse tipo de fonte histórica de origem médica), que, segundo a versão do acusado, teria no segundo dia de casamento começado a narrar relações que teve com outros homens (Carrilho e Mendonça, 1935: 34-48). Nas palavras do feminicida, com o passar dos meses Elaine teria demonstrado predileções absurdas, como o gosto pela vida noturna e pela nudez. Um dia, ao chegar do trabalho, Fernando "encontrou-a no banheiro, despida, em frente à janela aberta, ao alcance das vistas dos empregados do prédio próximo" (Carrilho e Mendonça, 1935: 34-48). Segundo Carrilho e Mendonça (1935: 39-40), "o examinado enxergara nas intimidades da esposa, hábitos e modos inadmissíveis nas pessoas de sua condição doméstica e social". Mas os fatos se agravariam no carnaval. Fernando afirmava não estar interessado na folia, mas Elaine mostrava-se muito animada com os folguedos. Em um dos dias da festa, saíram à rua, ele embriagou-se de cerveja, e ela de lança-perfume. No sexo que se seguiu, a esposa ter-lhe-ia feito "revelações muitos serias sobre o seu passado" (Carrilho e Mendonça, 1935: 42). A narração desses fatos foi feita de forma absolutamente romanceada pelos médicos no laudo, mostrando uma característica desse tipo de discurso que remete muito a suas ligações com os fait divers e a crônica policial de maneira geral. Esse modo de narrar constitui, com efeito, elemento de naturalização, destrinchando-se o máximo possível os circuitos das tramas afetivas dos uxoricidas e dos casais, aspecto que, no entanto, era questionado por juristas como Roberto Lyra e Nelson Hungria.

Esse é um caso, todavia, extremamente complexo, com diversas versões. Vale atentar para o fato de que o discurso pericial era fruto de grande polifonia discursiva — da versão de acusado, parentes, vizinhos, dos autos da política, de documentação judiciária de variada natureza etc. ${ }^{8}$. No caso de Fernando, esse amalgamento fluiu no sentido da caracterização do acusado como anormal, mas que deveria ser punido. A versão dos autos, explorada pelos peritos, firmava uma imagem de Fernando como sujeito ciumento, infiel sistemático, abusador da mulher, que deixava reclusa, sem poder nem pintar as unhas. Para os médicos, no momento do exame, um indivíduo relativamente culto e intelectualizado apresentou-se respeitoso, mas deprimido, mostrando-se emotivo ao falar da esposa, e narrava sua honra ferida pelo passado dela (Carrilho e Mendonça, 1935: 44). Concluíram, então, os peritos que não 
se tratava de indivíduo doente mentalmente, mas somente de temperamento esquizotímico, sensível, imaginativo, e, no momento do crime, não estava inconsciente. Deveria, portanto, ser considerado responsável penalmente.

É um caso de violência de gênero brutal sob o signo da honra. Diversos aspectos desse caso podem ser destacados. A narrativa dos peritos expressa o processo de decaimento de um homem, de uma masculinidade particular. Como nunca é demais lembrar, a medicina dá seus contributos discursivos para a produção cultural das expectativas do masculino correto socialmente (Albuquerque, 2013). Ou seja, um comportamento masculino inadequado, de alguma maneira, pesa na percepção dos acontecimentos pela peritagem psiquiátrica. Por sua vez, o comportamento feminino considerado "fora do padrão estabelecido para as 'mulheres honestas'" justificava, na fala dos acusados, "a violência como forma de disciplina", culpando, no fim das contas, a mulher pelas agressões sofridas" (LAGE \& NADER, 2013: 287-288). É o padrão da honra masculina ferida pela vivência da esposa anterior à relação, o que a tornou uma espécie de propriedade defeituosa por não cumprir as exigências maritais. Assim, a própria noção de ciúme confunde-se com a noção de honra ferida, como um orgulho maculado, sustentada ainda pela objetificação da mulher. Finalmente, ainda que afirmando a responsabilidade do acusado, os peritos alegaram que ele era um indivíduo emotivo e sensível. A ideia kretschmeriana de temperamento agiu, aqui, como uma das cenas possíveis da naturalização/ explicação científica do ato violento, ainda que ele não tenha sido exculpado pelo crime.

Apesar da importância do ciúme, a infidelidade feminina figurava no discurso pericial como fator preponderante de abalo moral, em alguma medida justificador da criminalidade passional. Não à toa, ainda que deslegitimassem a violência masculina em variados espaços e diversas intervenções nos anos 1930, médicos e juristas daqui e de outros espaços nacionais faziam "eco às inquietações masculinas em relação à fidelidade e à obediência das mulheres" (Virgilli, 2013: 95). É o que vemos no caso de Orlando Rodrigues, branco, brasileiro, 49 anos, farmacêutico, que entrou no MJRJ em junho de 1935 e ali fora examinado durante cinco meses por Heitor Carrilho e Armando Guedes Cabral, médico legista da polícia.

Segundo os autos, reproduzidos pelos peritos no laudo por nós analisado, Orlando atacou a facadas na descida de um bonde um primo a quem culpava pela separação da esposa (Carrilho; Cabral, 1935). Para esses médicos, o examinado não poderia ser condenado pelo crime porque, além da forte tara psicopática (uma hereditariedade mórbida) que carregava e um temperamento ciclotímico, a traição, como trauma afetivo incontornável, destruiu sua vida psíquica e o fez ter reações mentais patológicas (Carrilho; Cabral, 1935: 62-63).

0 caso de Orlando, além de mostrar a centralidade da infidelidade feminina para a justificação medicamente embasada da irresponsabilidade penal de passionais nos anos 1930, 
apresenta as ambivalências da conceituação médica. Como vimos, os indivíduos considerados verdadeiros passionais eram, na maioria das vezes, não de temperamento ciclotímico, mas leptossômicos esquizotímicos. Portanto, havia em certos casos indefinições nas relações necessárias entre o tipo de personalidade e temperamento e o trauma afetivo (traição ou ciúme).

Outro elemento importante na patologização pela psiquiatria de homens que matavam mulheres e outros homens por razões passionais nos anos 1930 dizia respeito ao corte de classe. Não obstante a maior parcela dos ingressos para exame e/ou internação no MJRJ ter sido, no período em tela, de indivíduos das classes subalternas, boa parte dos que tinham seus crimes passionais de alguma maneira explicados ou justificados, no conjunto de casos estudados, era de camadas medianas.

Esse é o caso de Almir Antônio, branco, casado, 30 anos, prático de farmácia, que em julho de 1940 ingressou no MJRJ para exames por ter assassinado sua mulher. Na visão dos médicos que escreveram seu laudo - dois médicos do próprio MJRJ discípulos de Carrilho - Almir era um indivíduo "leptossômico muito nervoso", "um homem tímido, acanhado, impressionável, hiperemotivo" (Azevedo e McDowell, 1940: 61). Para os médicos, a infidelidade comprovada de sua mulher, a qual andava com vestido excessivamente decotado e a quem flagrou com um homem em casa em trajes menores, foi o gatilho que faltava para o crime. Dessa maneira, impossível, na leitura dos psiquiatras, encontrar uma responsabilidade no seu ato. Aqui, a junção entre constituição e traição deu-se junto com aceitação integral, pelos peritos, do relato do paciente.

O que perpassa a maioria dos casos analisados é a ideia de que o ciúme da vítima e a consequente ofensa à honra na qual ele implicaria resultam em uma perspectiva culpabilizadora para a vítima. Há, contudo, casos em que o comportamento feminino, um eco ainda presente em justificativa de violências de gênero atualmente, surge de maneira ainda mais evidente como justificativa para o crime (LAGE \& NADER, 2013).

Notamos isso no relato de Augusto Palmeira, que no primeiro dia do ano de 1931 matou com dois tiros a esposa e depois tentou se suicidar. Várias versões do ocorrido circularam na época, mas os periódicos, no geral, ficaram do lado do acusado, retratando-o como um pobre coitado que se apaixonou por uma mulher de má vida. Na maior parte das versões veiculadas, mais uma vez, a culpa recaiu na mulher, lara, considerada adúltera, de vida transviada, que se perdeu no tumulto vertiginoso da vida fácil ${ }^{9}$. 0 certo é que no julgamento ocorrido em outubro de 1931 Augusto foi condenado a 12 anos de prisão. Três anos depois o condenado entrou com pedido de indulto, o qual foi julgado e negado pelo CPDF. Nesse primeiro pedido, a maioria do CPDF votou com o relator, Roberto Lyra; Heitor Carrilho foi voto vencido por apoiar o indulto. 
A perspectiva de Lyra (1932), na ocasião, era de que, no momento do crime, Augusto possuía total consciência. Já para Carrilho (1933; 1936), com base no ponto de vista do médico francês Maurice Fleury (no livro L'angoisse humaine, de 1924), sustentava que a real tentativa de suicídio significava uma psicopatia caracterizada principalmente pela perda do instinto de conservação da vida. 0 indivíduo, nesse estado, para Carrilho, deveria ser considerado incapaz de imputação (apud Brito, 1935: 89-106). Ao seguir Fleury, Carrilho adotava uma posição antidurkheimiana, uma vez que esse psiquiatra atrelava-se ao cânone alienista francês representado por Esquirol na abordagem do tema. Em outras palavras, o suicídio estaria ligado muito mais a causas biopsicológicas do que sociais.

No ano seguinte, em 1935, foi feito novo pedido alegando novamente que o crime teria sido cometido em estado de completa perturbação dos sentidos e da inteligência. No entanto, dessa vez, a argumentação de Carrilho convenceu os outros componentes do CPDF. 0 penitenciarista José Lemos de Brito, relator do segundo pedido, assim se referiu à argumentação de Carrilho: "Este é um caso em que a palavra do psiquiatra erudito deve ser mais do que em outros devidamente analisada" (Brito, 1935: 96). A certeza do adultério fazia sua aparição como elemento ainda mais severo que o ciúme, bem como a imagem social de homem correto que Augusto encarnava.

Para Roberto Lyra, voto vencido nesse caso, Carrilho e, por conseguinte, o próprio CPDF afrontaram a soberania do júri e do interesse social. Dessa forma, no seu modo de ver, o indulto representava uma impunidade e validava um tipo inaceitável de intervenção médica no âmbito da justiça penal. 0 que a justiça decidia era mais importante do ponto de vista social do que poderia dizer um laudo ou a ciência psiquiátrica como um todo, na sua visão, uma vez que o ponto de vista psiquiátrico era por demais focado no indivíduo. 0 promotor elaborou e reafirmou uma dicotomia acionada em outras ocasiões e com lastro importante na relação entre psiquiatria e justiça penal: se o direito era o social, a psiquiatria era 0 individual.

\section{A CONDENAÇÃO DO PASSIONALISMO SANGUINÁRIO}

D iante da análise dos casos, é necessário destacar que em alguns deles a psiquiatria procurou intervir na responsabilização dos acusados, o que demonstra que mesmo no campo psiquiátrico as considerações sobre as motivações de tais crimes não eram homogêneas e não exculpavam sempre os assassinos (como vimos em relação ao caso de Fernando Vasconcelos). Portanto, a apresentação de contraexemplos, da falta de consenso e homogeneidade dentro do mundo psiquiátrico forense, entre este e o mundo jurídico, e no mundo jurídico, é fundamental para fazer ver que não existia vetor único nem da decisão judicial, como já foi muito estudado, nem dos pareceres psiquiátricos do período. Apesar de os contornos de 
naturalização da violência e de patologização dos perpetradores terem realce no conjunto dos casos, as elaborações periciais não seguem o mesmo enredo, não há regularidade discernível.

Ainda assim, esses casos permitem-nos ver o agenciamento da psiquiatria na naturalização das motivações passionais dos crimes e a forte influência das conclusões psiquiátricas no desenrolar dos casos, sobretudo nos anos 1930. Ao mesmo tempo, fortalecia-se o movimento dos juristas pela criminalização dos crimes passionais, tendo como uma de suas principais figuras o jurista Roberto Lyra. Além de Lyra, outro jurisconsulto fortemente engajado na confrontação das absolvições dos passionais segundo argumentos psiquiátricos, criminológicos e psicológicos foi Nelson Hungria.

A atuação de Hungria nesse sentido é evidenciada no caso de João Moura, que em outubro de 1933 matou sua esposa a tiros em meio a rua Frei Caneca. 0 assassino resumiu suas razões na desconfiança que nutria acerca da fidelidade da mulher, o que, para Hungria, "não excusa(va) o crime, nem dirimi(iria) a culpa" (Hungria, 1931: 95-99), principalmente porque João não cumpria seu papel de esposo, não provendo o lar, tendo outros amores e tendo contraído doenças venéreas.

Indivíduos como João de Moura, para Hungria, dizendo-se paladinos da honra conjugal, não agiam por paixão, mas por maldade. Na intimidade conjugal, que deveria ser foco de atenção do juiz, esses homens dificilmente cumpriam seu papel, fazendo as esposas submissas, às vezes deixando a família na miséria. Dessa forma, as mulheres acabavam (ou não), cometendo adultério, já que, na ótica do magistrado, elas mereciam viver e tentar mudar. Nada justificava matar "a esposa em nome de um monstruoso dever de honra" (Hungria, 1931: 98).

Ao longo dos anos 1930 Hungria fazia suas comuns críticas ao júri e ao rótulo de crime passional, sobretudo no que se referia à força de convencimento que a psiquiatria poderia ter no tribunal popular. Para ele, essa especialidade médica era muito responsável por tais absolvições. Rememorando o período entre as décadas de 1920 e 1930, o jurista afirmou, em texto de 1943, que a psiquiatria reinou perante o júri naquele contexto: "Foi o período áureo do passionalismo sanguinário [...], licenciado sob a estapafúrdia rubrica de 'privação dos sentidos'" (Hungria apud Sontag, 2009: 268).

Não obstante ter respeitado a psiquiatria como adversária científica a altura do direto penal em certas circunstâncias nos anos 1930, na década de 1940, Nelson Hungria posicionou-se abertamente contra o biologicismo (ou o que chamava de criminofilia) e o intercurso de outros saberes no direito penal, tirando seu caráter puro e normativo. Foi nesse contexto que ele ressaltou que a substituição de juízes por médicos era a mais pura expressão da anarquia: "A psiquiatria ao deixar o templo de Esculápio para entrar no Temis, há de curvar-se ante os altares e rezar nos seus ritualis libri" (Hungria, 1939: 92). A sua argumentação indica-nos 
que a psiquiatria conseguia, de fato, absolver nos anos 1930, o que gerava tensões bem marcadas entre os campos jurídico e psiquiátrico que se intensificaram na década seguinte.

Contudo, o que notamos no movimento jurídico que culminou nas modificações do Código Penal de 1940 é que este acompanhou um processo de anseio civilizacional da sociedade brasileira. É possível que no contexto dos anos 1920 até a década de 1940 tenha existido aumento de crimes passionais diante de uma configuração social na qual algumas mulheres passaram a ter novas opções e aspirações, gerando conflitos de gênero - isso porque a tentativa de controle do comportamento feminino se tornaria, para elas, menos tolerável. Mas a campanha de Lyra e Hungria não refletiu necessariamente uma consciência feminista, no sentido de que não demandavam explicitamente a independência das mulheres ou o fim de hierarquias de gênero mais amplas e profundas (Besse, 1989).

Hungria foi especialmente denunciador das condições de vida das mulheres submissas a maridos que não cumpriam seus papéis de esposos e deixavam tanto elas quanto sua família na miséria. Contudo, nessa lógica, a possiblidade de melhoria de vida implicava na busca por novos parceiros. Argumentos dessa natureza acabaram por reafirmar certa autoridade do marido sobre a mulher quando este cumpria bem seus papéis sociais.

É, contudo, nas palavras de Lyra que encontramos maiores tensões nesse sentido. Para ele, existiriam "aspectos irremediáveis da inferioridade feminina" (Besse, 1989: 657). Lyra era ainda contra o voto feminino, considerava que mulheres não casadas tinham mais chances de cair na perdição e achava que o melhor que elas possuíam era a beleza física. Não se debatia, ainda, que crimes passionais se seguiam à violência cotidiana, à violência doméstica por parte de bons ou maus provedores, que findava por matar mulheres.

Apesar disso, nas suas intervenções ao longo dos anos 1930, Lyra (1932: 10) afirmava a continuidade de sua campanha de esclarecimento da consciência pública contra os crimes passionais, realizando higiene social e serviço de ordem pública. Ele se dizia numa cruzada contra a cultura romântica que dominava o espírito brasileiro, e no prefácio que escreveu para a edição brasileira de Delito Passional na Civilização Contemporânea, de Ferri, Lyra (1934) enfatizou que no momento de desordem que o Brasil vivia, a condenação e a intimidação dos passionais configuraria elemento civilizacional importante.

Em uma perspectiva geral, reiterando a tese seminal de Besse (1989), é possível afirmar que a contestação mais ferrenha dos crimes passionais a partir da década de 1930 demonstra preocupação social que transparece valores civilizatórios daquele contexto (Besse, 1989). Contudo, essas tensões não respondem a anseios sociais emancipatórios para as mulheres e, ainda que esse movimento civilizatório contemple crimes de violência contra as mulheres por meio da jurisprudência desses crimes, eles ainda esbarraram em muitos preconceitos sociais. 


\section{CONSIDERAÇÕES FINAIS}

$\mathrm{O}$

objetivo deste texto foi apresentar como o discurso psiquiátrico e médico psicológico no geral, assim como o discurso jurídico psiquiatricamente informado, buscaram explicar, ao longo da década de 1930, a chamada criminalidade passional. Alguns termos procuravam dar conta do estado ou da condição de morbidez afetiva sob os quais os agressores teriam agido: acentuação da emotividade; emotividade patológica; exaltação emocional. Todas elas seriam as condições psicológicas da completa perturbação dos sentidos e da inteligência que a lei penal prescrevia.

Seguindo os laudos médicos e outros documentos, especialmente jurisprudência e pareceres do CPDF, além de textos médicos e jurídicos de época, encontramos que os argumentos ligados ao despertar dos estados de instabilidade de ordem patológica ou temperamental que culminaram nos assassinatos foram múltiplos: uma traição da esposa/parceira ou a suspeita, ciúme de relações da parceira em outras esferas da vida (trabalhista, por exemplo, ou familiar), a vida passada da mulher com quem se relacionavam.

Acompanhar a argumentação médica nos laudos psiquiátricos é, então, uma maneira de ter acesso ao sentido histórico de uma das formas de explicação para a violência masculina contra as mulheres ou contra outros homens. Ainda que em alguns casos o argumento médico não tenha sido suficiente para justificar as violências ou inocentar os acusados — tanto na visão dos psiquiatras quanto na dos juristas —, elas foram utilizadas quando se procurou na constituição do agressor a origem biopsicológica dessas violências, entendidas, assim, como disfunções de ordem emocional e afetiva.

Os estudos de gênero têm, dessa forma, contribuído para a complexificação e a compreensão das relações entre homens e mulheres - e daquilo que não se enquadra nesse binarismo e o questiona - , e não para a busca por uma causa essencial, abstrata e a-histórica da subordinação feminina e da dominação masculina (Pinsky, 2009). Diante da efervescência social com a crescente ocupação de espaços públicos por algumas mulheres no período, encontramos também repercussão cada vez maior de tais crimes, acompanhada de verdadeira preocupação da medicina forense em intervir nesse sentido. Em meio a ruídos e dissensos no corpo dos profissionais que participaram das respostas a tais crimes, não podemos descartar a defesa da vida dessas mulheres. Contudo, no conjunto analítico aqui exposto, trazemos também os indícios da permanência de visões essencializadoras do feminino nas vozes dos próprios profissionais.

Por meio de alguns laudos vemos que o homicida foi em alguma medida vitimizado, e mesmo enaltecido, compreendida a agressão como um momento de descontrole motivado por amor, e não como reflexo de uma cultura. Em alguns casos, a ideia de 
instabilidade patológica chegou até a absolver acusados de assassinato de suas companheiras. Ainda que responsabilizados total ou parcialmente, os agressores sofreram, em alguma medida, atenuação social se considerados pelo viés patologizante. A patologia como algo que incapacita demonstra nesses casos que o homem, ser racional por excelência (dentro dos discursos médico-científicos do contexto (Toledo e Vimieiro, 2018), sofre de perturbação dos sentidos e torna-se irracional nesse contexto, justificando, ao menos em parte, sua conduta violenta.

Tendo em vista a historicidade das ciências, não se trata aqui de julgar tais pareceres como certos ou errados, mas de compreender em que saberes eles se ancoravam e o impacto que tiveram sobre os casos e sobre o questionamento e a manutenção de tais violências. A naturalização — no sentido de reprodução não problemática - da violência de gênero nesse relevante período da história do Brasil deu-se como o resultado de um processo que envolveu diversas esferas da sociedade. Uma delas, os saberes médico-jurídicos e periciais.

Por fim, cabe frisar que enquanto especialidade médica, voltada, portanto, para a meIhoria da saúde, as constatações dos laudos produziram efeitos invisibilizadores das violências quando a ciência dizia que elas refletiam algo de ordem biológica. Assim, a patologização e/ ou assunção de anormalidade nesses sujeitos foram um argumento que permitiu a atenuação de sua culpa pela morte de outro ser humano, seguindo códigos e valores que participaram da formulação das entidades patológicas associadas aos crimes ditos passionais. Em outras palavras, é absolutamente historicizável a noção de que desequilíbrio masculino de alguma natureza possa ser a causa desses crimes. Dessa maneira, a psicopatologia serviu ao seu abrandamento, sobretudo sob a ótica da defesa da honra.

Procuramos aqui demonstrar que historicamente no Brasil o despertar de elementos considerados patológicos passava, necessariamente, por uma noção de falta de autonomia feminina e objetificação das mulheres. A luta pela desconstrução dessa ideia surgiu a partir da década de 1970 em movimentos que reivindicam que os crimes de "amor", associados muitas vezes a distúrbios psicológicos, jaziam sobre defesa de capital simbólico masculino que passava pelo corpo e pela vida de outrem — as mulheres.

Abordar a história do crime passional é, portanto, historicizar a ponta do iceberg. Atualmente, vemos como o feminicídio é o resultado de outras formas de abuso ainda mais invisibilizadas naquele contexto. Sobretudo as violências psicológica e moral, ainda hoje bastante negligenciadas, não configuravam violências nomeadas, problematizadas e combatidas na mesma medida, o que não implica em sua inexistência ou na inexistência de seus impactos. 


\section{NOTAS}

1 Para fins analíticos, consideram-se sob esse rótulo os homicídios e as tentativas de homicídios cometidos por razões tidas culturalmente como amorosas - por círculo sociocultural de relações imediatas dos envolvidos, familiares, imprensa, polícia, instituições penais e médicas etc. - , na maioria das vezes perpetrados por homens contra mulheres. Trata-se de enquadramento sociocultural complexo e variável historicamente (Cetina, 2015). Pode ser também um ato de violência direcionado ao indivíduo que supostamente ameaça tal vínculo amoroso: o amante, a amante, o deflorador, os parentes da vítima etc. Na historiografia inglesa são mais comuns expressões que podem ser traduzidas como violência marital ou doméstica. Diz respeito a um dos enquadramentos históricos da violência de gênero na modernidade, tornando-se elemento para a compreensão da ideologia da virilidade (Virgilli, 2013).

2 Nos sendo aqui impossível citar o que há de mais importante na produção nacional, vale o crédito a estudos de relevância e impacto na historiografia nacional: Corrêa (1983), Soihet (1997) e Engel (2001). Para um balanço nacional, ver Rinaldi (2015).

3 Segundo o presidente do júri do Distrito Federal em fins dos anos 1930, Ary Azevedo (1939), de 1930 até 1939, em todos os casos de evocação da dirimente, os réus de competência do júri foram para exame psiquiátrico, e na maior parte dos casos a decisão penal final coincidiu com os laudos. Os exames psiquiátricos, os conhecimentos e esclarecimentos por eles trazidos para a Justiça Criminal, eram necessários para a sobrevivência do Tribunal do Júri e para a legitimidade de suas decisões.

4 Todos os nomes de acusados e condenados por crimes passionais descritos e analisados aqui foram inventados com base nas iniciais reproduzidas na documentação.

5 Heitor Carrilho é ator-chave neste texto. Como ficará claro, ele subscreve a maior parte dos laudos de casos passionais analisados e é o psiquiatra com maior atuação forense na capital federal entre os anos 1920 e 1930. Para compreensão mais abrangente dessa personagem, ver Dias (2015).

6 Utilizamos para esta análise a primeira edição em espanhol de 1947, baseada na $18^{a}$ edição alemã de 1946 e traduzida pelo neuropsiquiatra espanhol José Solé Sagarra, ex-aluno de Kretschmer. Nas partes em que sintetiza sua teoria, Kretschmer manteve o texto do início dos anos 1920 (Kretschmer, 1947).

7 Os leptossômicos (lepto = delgado, soma = corpo) eram indivíduos com pouca gordura e crescimento longitudinal, sobretudo dos membros superiores. Eram pessoas magras, em extremo raquíticas, permanecendo assim ao longo da vida. 0 tipo atlético tem grande desenvolvimento do esqueleto, da musculatura e da pele, sendo o grupo mais reduzido estatis- 
ticamente, e expressa o ideal artístico de beleza masculina. Já os pícnicos são indivíduos de acentuada adiposidade com pescoço curto.

8 Os laudos apresentam saberes que serão validados ou não pelo mundo jurídico. Tal validação dependia de muitos fatores, desde o nível de formalização dos processos, passando pela coerência do conteúdo do que foi elaborado com base no discurso médico e sua adequação às normativas jurídicas, o status socioprofissional das ciências articuladas, até a adequação desses conhecimentos com as retóricas de convencimento inscritas nos valores socioculturais das classes intelectualizadas. A perícia psiquiátrica e o laudo decorrente dela são atos científicos específicos e interagem com os poderes de julgamento dos homens do direito, com suas razões jurídicas, colocando outros discursos e outras racionalidades em cena e em disputa. Mesmo numa relação desigual com os magistrados, os peritos também desenvolveram estratégias de convencimento. A justiça criminal, por seu turno, testou os saberes postos em jogo com base nas expectativas e nos interesses próprios de juízes, advogados e promotores nos julgamentos, cada qual fazendo usos específicos. Nessas relações complexas, as controvérsias e os dissensos do mundo científico — o psiquiátrico, principalmente — pousaram também nos espaços jurídicos. Na sua realização prática, esses laudos buscavam relacionar dados de várias naturezas para chegar a uma conclusão que explicasse o ato criminoso cometido (Dumolin, 2000: 204-208).

9 Para análise detalhada da cobertura da imprensa e de outros aspectos desse caso, conferir a tese de Dias (2015: 357-366).

\section{REFERÊNCIAS BIBLIOGRÁFICAS}

ALBUQUERQUE, D. M. Nordestino: invenção do falo - uma história do gênero masculino. São Paulo: Intermeios, 2013.

AZEVEDO, A. A perícia psiquiátrica nos processos penais. Arquivos do Manicômio Judiciário do Rio de Janeiro, Rio de Janeiro, ano X, v. 1 e 2, p. 7-11, 1939.

AZEVEDO, F. de; MC DOWELL, F. L. Laudos e Documentos Psiquiátrico-Legais. Hiperemotividade. Arquivos do Manicômio Judiciário do Rio de Janeiro, Rio de Janeiro, ano XI, v. 1 e 2, p. 60-67, 1940.

BESSE, S. Crimes of Passion: The Campaign against Wife Killing in Brazil, 1910-1940. Journal of Social History, v. 22, n. 4, p. 653-666, 1989.

BRASIL. Decreto n. 847, de 11 de outubro de 1890. Promulga o Código Penal. Disponível em: https://www. planalto.gov.br/ccivil_03/decreto/1851-1899/d847.htm. Acesso em: 23 dez. 2019.

BRITO, J. G. Pareceres e Promoções. Conselho Penitenciário do Distrito Federal. A tentativa séria de suicídio em seguida ao homicídio. Arquivos do Manicômio Judiciário do Rio de Janeiro, Rio de Janeiro, ano VI, v. 1 e 2, p. 89-106, 1935. 
CARRILHO, H. Objetivos da Perícia Psiquiátrica. Arquivos do Manicômio Judiciário do Rio de Janeiro, Rio de Janeiro, ano III, v. 1 e 2, p. 5-23, 1932.

CARRILHO, H. Os criminosos passionais e o sursis. Arquivos do Manicômio Judiciário do Rio de Janeiro, Rio de Janeiro, ano VII, v. 1 e 2, p. 3-15, 1936.

CARRILHO, H. Psicopatologia da paixão amorosa e seu aspecto médico-legal. Arquivos do Manicômio Judiciário do Rio de Janeiro, Rio de Janeiro, ano IV, v. 1 e 2, p. 33-59, 1933.

CARRILHO, H.; BARBOSA, Morethzohn. Laudos e Documentos Psiquiátricos-legais. Psicose de involução. Delírio de Ciúmes. Arquivos do Manicômio Judiciário do Rio de Janeiro, Rio de Janeiro, ano VII, v. 1 e 2, p. 97-106, 1936.

CARRILHO, H.; CABRAL, Armando G. Laudos e Documentos Psiquiátricos-legais. Tentativa de Homicídio. Constituiç̧ão ciclotímica. Arquivos do Manicômio Judiciário do Rio de Janeiro, Rio de Janeiro, ano VI, v. 1 e 2, p. 59-65, 1935.

CARRILHO, H.; MENDONÇA, Bourguy de. Laudos e Documentos Psiquiátrico-Legais. Uxoricídio. Arquivos do Manicômio Judiciário do Rio de Janeiro, Rio de Janeiro, ano VI, v. 1 e 2, p. 34-48, 1935.

CAULFIELD, S. Em defesa da honra: moralidade, modernidade e nação no Rio de Janeiro (1918-1940). Campinas: Editora Unicamp, 2000.

CETINA, S. Entre la emoción y el honor: Crimen pasional, género y justicia en la ciudad de México, 19291971. Estudios de Historia Moderna y Contemporánea de México, vol. 50, p. 28-44, 2015.

CORRÊA, M. Os Crimes da Paixão. São Paulo: Brasiliense, 1983.

DIAS, A. A. T. Arquivos de ciências, crimes e loucuras: Heitor Carrilho e o debate criminológico do Rio de Janeiro entre as décadas de 1920 e 1940. Tese (Doutorado em História das Ciências e da Saúde) - Fundação Oswaldo Cruz. Rio de Janeiro: Casa de Oswaldo Cruz, 2015.

DUMOLIN, L. L' expertise judiciaires dans la construction du jugement: de la ressource à la contrainte. Droit et Socièté, n. 44-45, p. 199-223, 2000.

ENGEL, M. G. Paixão, crime e relações de gênero (Rio de Janeiro, 1890-1930). Topoi [online], vol.1, n.1, p.153-177, 2000.

ESTEVES, M. Meninas perdidas: os populares e o cotidiano do amor no Rio de Janeiro. Rio de Janeiro: Paz e Terra, 1989.

FERRI, E. O delito passional na civilização contemporânea. São Paulo: Saraiva, 1934.

FOYSTER, E. Marital violence: an English family history. Cambridge: Cambridge University Press, 2005.

HARRIS, R. Assassinato e loucura: medicina, leis e sociedade no fin de siécle. Rio de Janeiro: Rocco, 1993.

HUNGRIA, N. Acórdão. Apelação Criminal n 783. Arquivos do Manicômio Judiciário do Rio de Janeiro, Rio de Janeiro, ano X, v. 1 e 2, p. 91-93, 1939.

HUNGRIA, N. Juízo da sexta vara criminal. Arquivos do Manicômio Judiciário do Rio de Janeiro, Rio de Janeiro, ano II, v. 1 e 2, p. 95-98, 1931.

JESÚS, B. de. A (des)naturalização do gênero e da sexualidade: algumas reflexões sobre o acesso das/dos transexuais à cidadania no Brasil. In: SEMINÁRIO DE PESQUISA DA FACULDADE DE CIÊNCIAS SOCIAIS 
DA UFG, 2., 2011, Goiânia. Anais [...]. 2011. Disponível em: <https://files.cercomp.ufg.br/weby/up/253/o/ Bento_Manoel_de_Jesus.pdf>. Acesso em: 15 mar. 2020.

KRETSCHMER, E. Constitución y Carácter: investigaciones acerca del problema de la constitución y de la doctrina de los temperamentos. Barcelona/Madri: Editorial Labor, 1947.

LAGE, L.; NADER, M. B. A legitimação da condenaç̧ão social. In: PINSKY, C. B.; PEDRO, J. M. P. (Org.). Nova História das Mulheres no Brasil. São Paulo: Contexto, 2013, p. 286-312.

LYRA, R. Amor e responsabilidade criminal. São Paulo: Saraiva, 1932.

LYRA, R. Prefácio. In: FERRI, E. O delito passional na civilização contemporânea. São Paulo: Saraiva, 1934, p. I-IX.

MATOS, M. I.; BORELLI, A. Espaço feminino no mercado produtivo. In: BASSANEZI, C. P.; PEDRO, J. M. (orgs.). Nova história das mulheres no Brasil. São Paulo: Contexto, 2012. p. 126-147.

PEIXOTO, A. Criminologia. Rio de Janeiro: Guanabara, 1933.

PINSKY, C. B. Estudos de Gênero e História Social. Revistas Estudos Feministas, Florianópolis, v. 17, n. 1, p. 159-189, abr. 2009. Disponível em: <http://www.scielo.br/scielo.php?script=sci_arttext\&pid=S0104026X2009000100009\&lng=en\&nrm=iso>. Acesso em: $17 \mathrm{mar}$. 2020. https://doi.org/10.1590/50104026X2009000100009

RABINOWICZ, L. O crime passional. São Paulo: Saraiva \& Cia, 1934.

RINALDI, A. A sexualização do crime no Brasil: Um estudo sobre criminalidade feminina no contexto de relações amorosas (1890-1940). Rio de Janeiro: Mauad X/Faperj, 2015.

SECRETO, M. V. Maldita leitura. História Unisinos, v. 9, n. 3, p. 211-217, 2005.

SOIHET, R. Condição feminina e formas de violência: mulheres pobres e ordem urbana (1890-1920). Rio de Janeiro: Forense Universitária, 1989.

SONTAG, R. "A eloquência farfalhante da tribuna do júri". 0 Tribunal popular e lei em Nelson Hungria. Revista de História, São Paulo, v. 28, n. 2, p. 267-302, 2009. https://doi.org/10.1590/S0101-90742009000200010

STRANGE, C.; CRIBB, R.; FORTH, C. (orgs.). Honour, violence and emotion in history. Londres: Blomsbury, 2014.

TOLEDO, E. T. de; VIMIEIRO, A. C. A Vida Sexual, de Egas Moniz: eugenia, psicanálise e a patologização do corpo sexuado feminino. História, Ciências, Saúde - Manguinhos, Rio de Janeiro, v. 25, supl. 1, p. 69-86, ago. 2018. https://doi.org/10.1590/s0104-59702018000300005

VIRGILLI, F. Virilidades inquietas, virilidades violentas. In: CORBIN, A.; COURTINE, J.-J.; VIGARELLO, G. (orgs). História da Virilidade: a virilidade em crise. Séculos XX-XXI. Petrópolis: Vozes, 2013. v. 3. p. 82-107.

WATSON, K. Forensic Medicine in Western Society: A History. Londres/Nova York: Routledge, 2011. 